\title{
Compact RFID Enabled Moisture Sensor
}

\author{
Umar Hasan KHAN ${ }^{1}$, Bilal ASLAM ${ }^{1}$, Muhammad Awais AZAM ${ }^{1}$, Yasar AMIN ${ }^{1,2}$, \\ Hannu TENHUNEN ${ }^{2,3}$ \\ ${ }^{1}$ ACTSENA Research Group, University of Engineering and Technology, 47050-Taxila, Pakistan \\ 2 iPack VINN Excellence Center, Royal Institue of Technology, SE-16440, Stockholm, Sweden \\ ${ }^{3}$ TUCS, University of Turku, Turku-20520, Finland \\ umar.hasan@uettaxila.edu.pk
}

Manuscript received June 08, 2016

\begin{abstract}
This research proposes a novel, low-cost RFID tag sensor antenna implemented using commercially available Kodak photo-paper. The aim of this paper is to investigate the possibility of stable, RFID centric communication under varying moisture levels. Variation in the frequency response of the RFID tag in presence of moisture is used to detect different moisture levels. Combination of unique jaw shaped contours and T-matching network is used for impedance matching which results in compact size and minimal ink consumption. Proposed tag is $1.4 \times 9.4 \mathrm{~cm}^{2}$ in size and shows optimum results for various moisture levels upto $45 \%$ in FCC band with a bore sight read range of $12.1 \mathrm{~m}$.
\end{abstract}

\section{Keywords}

Radio Frequency Identification (RFID), moisture sensor, T-matching

\section{Introduction}

Internet of things (IoT) is composed of multitude of smart objects that are connected to the internet via wired and/or wireless networks [1-4]. These objects need RFID tags, sensors, actuators, etc. not only to sense the environment but to communicate with each other as well. With the growing demands and rapid development of communication technology, research on integrating sensors with RFID tags has gained interest [5-8]. Embedding sensor element in RFID tags reduces the cost of setting up a sensor system but also paves way for various applications of RFID to be deployed. RFID-based sensors are used in various applications from food items to seepage detection, and from crops health monitoring to pharmaceutical tracking. In the food industry, RFID sensors have been used to detect the moisture level in shelled peanuts [9]. For seepage detection, RFID sensors can be embedded in walls. In moist surroundings, the difference in the backscattered received signal yields degradation in terms of dielectric losses [10]. Beside other applications, RFID tags are used in the field of agriculture. Inkjet-printed RFID tags based on paper substrate can be used for monitor- ing soil moisture [11]. RFID sensors are as much usable in the field of medicine as they are in any other field. Within the scope of medicinal application, the moisture level of patient's wound can be readily monitored using RFID tags [12]. Moisture detection in baby diapers is yet another successful commercial application that makes use of RFID tags [13].

This paper presents a compact RFID tag equipped with the capability to act as a moisture sensor that covers the FCC band of (902-928 MHz) with self-calibrated functionality. The proposed antenna uses the widely available paper substrate which gives the benefit of flexibility, nature friendly and one step closer to green electronics. The proposed antenna structure utilizes T-matching technique for conjugate impedance matching with RFIC without the meandering structure thereby reducing the quantity of conductive ink required for the realization of the tag. The effect of moisture on the antenna is also analyzed to guage the likelihood of stable RFID communication under various moisture levels. The proposed tag is an excellent choice for the IoT especially for identifying small objects in the smart room [14].

\section{Antenna Design}

The proposed sensing tag is derived from the combination of dipole antenna and meander line antenna [15], [16]. The choice of simple antenna provides not only reduction in size but also leads to lesser conductive ink consumption. End-tip loading and matching structure over the simple antenna is a common way to transform the path of the surface current and regulate the input impedance with the purpose of scaling down and tuning the tag [17]. Based on the previous ideas, the proposed layout included a method to amend the shape-factor of end-tip loading to increase the effective aperture of the antenna. Therefore, unique jaw-shaped contours are added at the end of the structure to increase the effective aperture of the antenna. The parametric optimization of antenna aperture is carried out to achieve the maximum effective aperture in the vicinity of reader, which automatically increases the gain of the tag. Gain is directly proportional to the effective aperture, so, the maximum available power at 


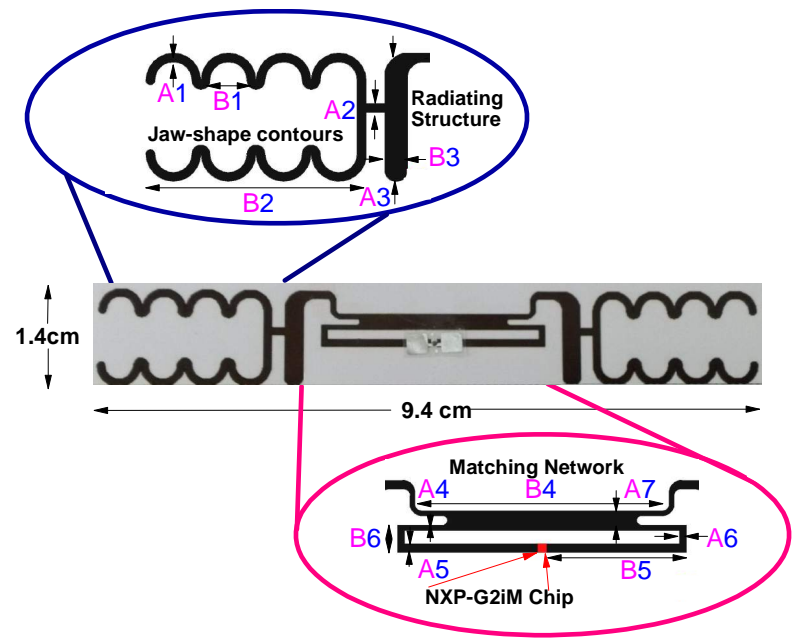

Fig. 1. Geometry of RFID moisture sensor.

the antenna terminal $P_{\text {Terminal }}$ is:

$$
P_{\text {Terminal }}=\frac{E I R P \times \lambda^{2}}{(4 \pi d)^{2}} G_{\text {ant }}
$$

where $\lambda$ is the wavelength, $G_{\text {ant }}$ is the gain of the antenna and $E I R P$ is the effective isotropic radiated power.

All of the power available at the antenna terminal is not delivered to the RFID chip. The actual power available to the RFID chip is significantly less depending upon the antenna mismatch factor $\Gamma$, which is determined by the impedance matching between the tag antenna and the RFID chip. Good impedance match is, therefore, imperative. The mismatch factor $\Gamma$ is defined as:

$$
\Gamma=\frac{4 R_{a} R_{c}}{\left|Z_{a}+Z_{c}\right|^{2}}
$$

where $Z_{c}=R_{c}+\mathrm{j} X_{c}$ is the chip impedance and $Z_{a}=R_{a}+\mathrm{j} X_{a}$ is the antenna impedance.

RFID chips are capacitive, so the antenna needs to be inductive for efficient impedance matching. Maximum power is transferred under conjugate matching [18], [19], where the capacitive susceptance of the chip is cancelled by the inductive reactance of the antenna. After various iteration, based on this numerical analysis, a compact antenna structure is achieved that consumes less conductive ink as shown in Fig. 1 and it's parameters are shown in Tab. 1. The read-range of the proposed antenna is given as:

$$
r_{\max }=\frac{\lambda}{4 \pi} \sqrt{\frac{\mathrm{EIRP} \times G_{\mathrm{ant}} \times \Gamma}{P_{\text {chip }}}}
$$

where $r_{\max }$ is the maximum distance between the reader and the tag and $P_{\text {chip }}$ is the minimum power required for the chip to initiate the back scattering principle.

Read range can be improved by optimizing the gain and impedance matching. Reduction in the operating power and improved sensitivity of the RFID chip can also enhance the read range.

\begin{tabular}{|c|c|c|c|c|c|c|c|}
\hline $\mathbf{( m m})$ & $\mathbf{1}$ & $\mathbf{2}$ & $\mathbf{3}$ & $\mathbf{4}$ & $\mathbf{5}$ & $\mathbf{6}$ & $\mathbf{7}$ \\
\hline $\mathbf{A}$ & 1 & 1 & 14 & 0.6 & 1 & 0.8 & 2.2 \\
\hline $\mathbf{B}$ & 4 & 24 & 2.5 & 28 & 15.8 & 0.8 & \\
\hline
\end{tabular}

Tab. 1. Antenna structure dimension.

\section{Antenna as Moisture Sensor}

Dielectric properties of the material depends on the interaction between the material and the electromagnetic radiations. Most important dielectric property is the complex permittivity which is defined as:

$$
\varepsilon^{*}=\varepsilon^{\prime}-j \varepsilon^{\prime \prime}
$$

Complex permittivity reflects the ability of the material to couple with electric energy from the electromagnetic fields. Dielectric constant $\left(\varepsilon^{\prime}\right)$ represents the ability of material to store the electromagnetic energy, and the loss factor $\left(\varepsilon^{\prime \prime}\right)$ highlights the ability of the material to convert stored electromagnetic energy into thermal energy. The ratio of the imaginary and real part of complex permittivity is known as loss tangent. Loss tangent determine the electromagnetic energy lost as heat.

Water is a dipole compound that couples the electromagnetic radiations very efficiently. So, as a result both the dielectric constant and the loss tangent are affected in the presence of moisture. Many researchers have tried to establish an empirical relation between moisture content and the dielectric properties [20-23]. General consensus is that both the dielectric constant and loss tangent increases with increased moisture content.

The properties of tag antenna must vary in a predictable manner with varying moisture levels in order to function as a moisture sensor. The proposed antenna design shows linear changes in impedance and frequency response under various relative moisture (RM), to achieve moisture sensor. RM corresponds to different dielectric values at which the tag must be detectable. This is discussed in detail in the next section.

\section{Parametric Analysis}

The main challenge in RFID tag design is to match the impedance of the tag to RFID chip in the desired band. A low cost NXP UCODE G2iM chip with an impedance of $21.2-\mathrm{j} 199.7 \Omega$ at $915 \mathrm{MHz}$ is integrated within the structure, therefore a conjugate matched input impedance of $21.2+\mathrm{j} 199.7 \Omega$ is required from the proposed antenna at this frequency. But, the chip impedance does not remain constant over the FCC band, so antenna must be matched all over the band to achieve wide bandwidth. T-matching network and jaw-shaped contours (semi-circles) are utilized in the proposed tag for impedance matching to achieve wider bandwidth. The parametric analysis is carried out on the jaw-shaped contours and matching network to achieve the required resistance and inductive reactance for the proposed antenna in FCC band. 


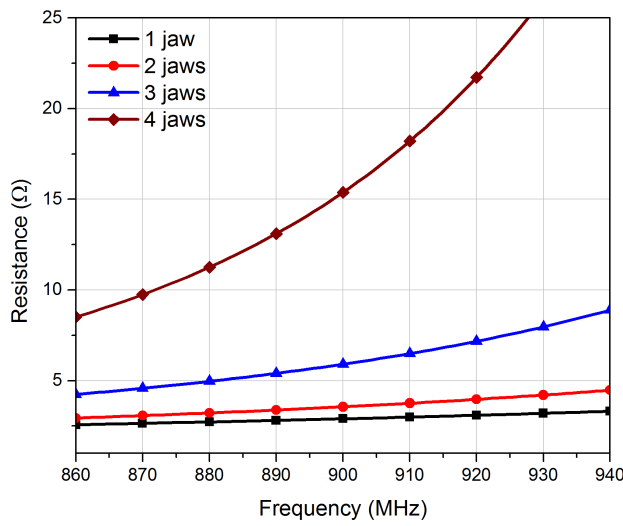

(a)

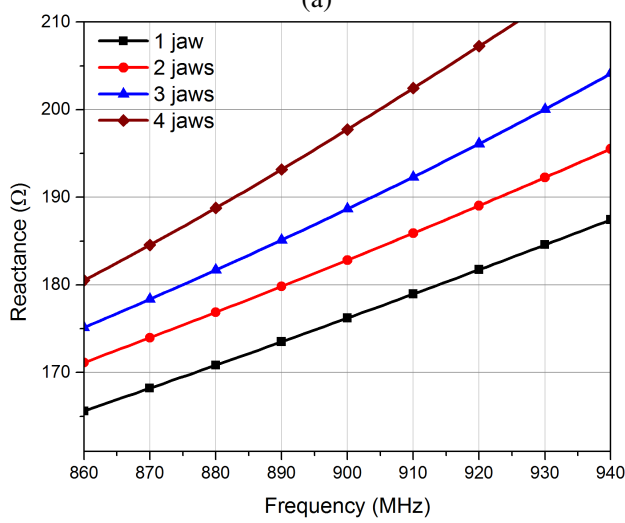

(b)

Fig. 2. Effect of jaw count on (a) resistance and (b) reactance.

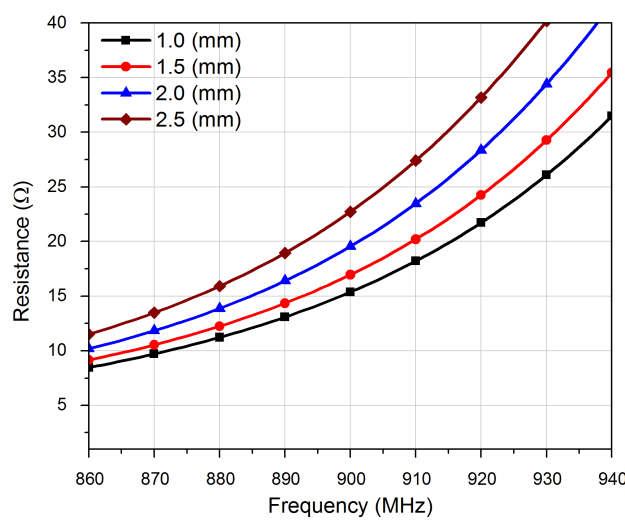

(a)

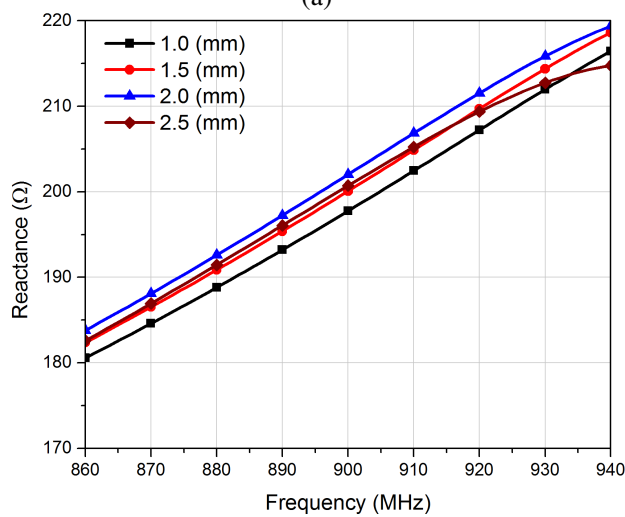

(b)

Fig. 3. Effect of A1 on (a) resistance and (b) reactance.

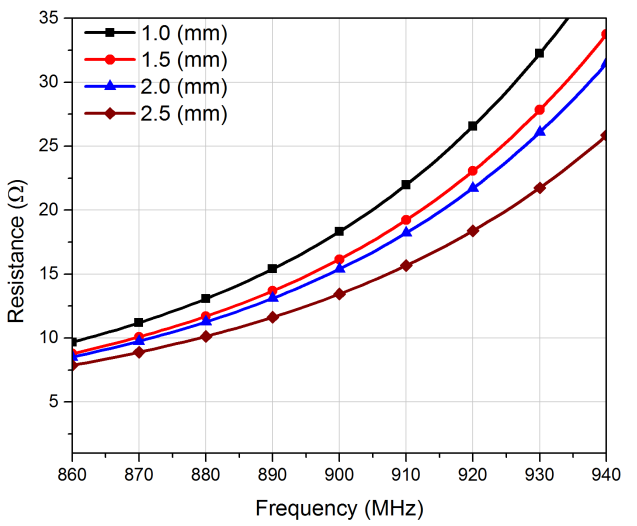

(a)

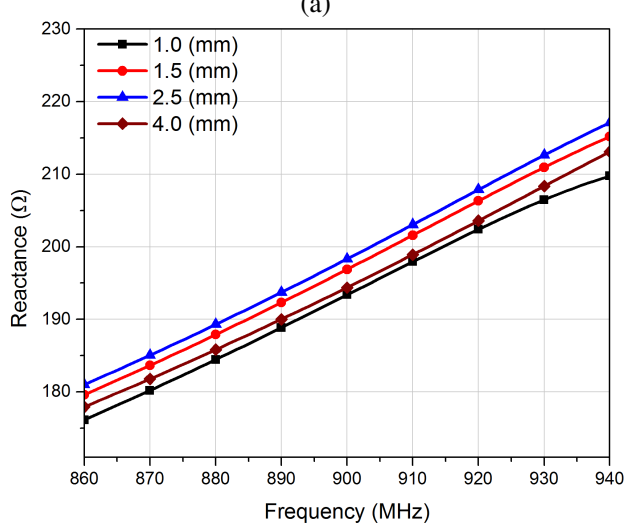

(b)

Fig. 4. Effect of B3 on (a) resistance and (b) reactance.

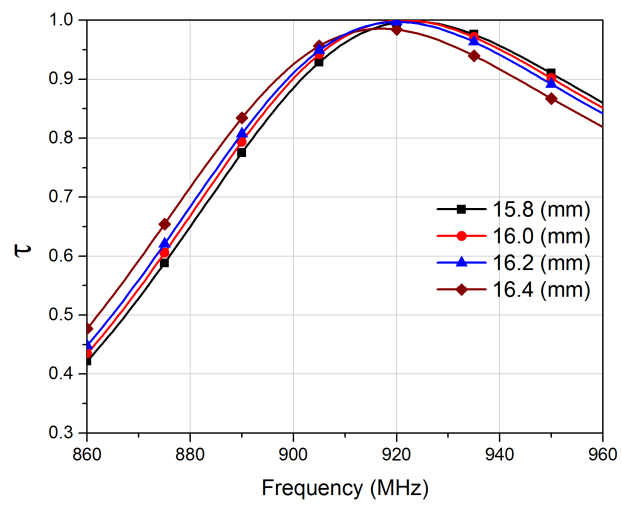

(a)

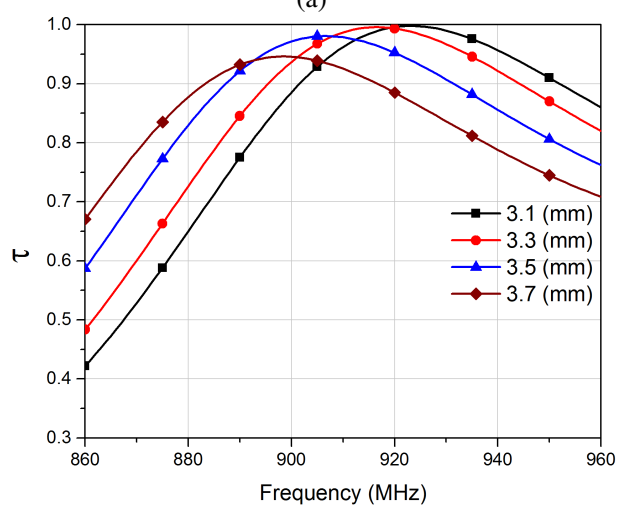

(b)

Fig. 5. Effect on return loss due to (a) B5 and (b) B6. 


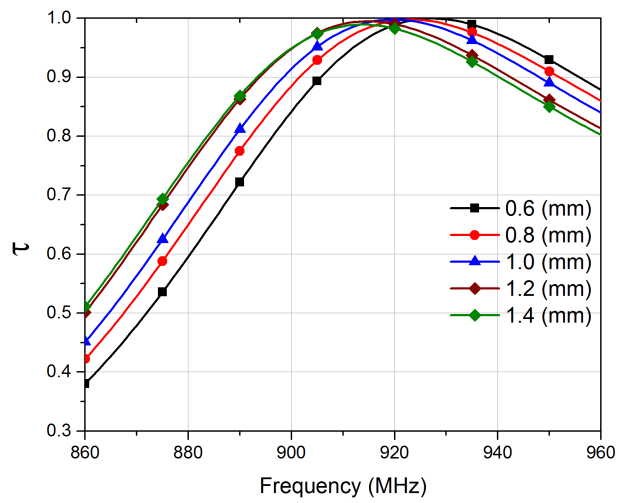

(a)

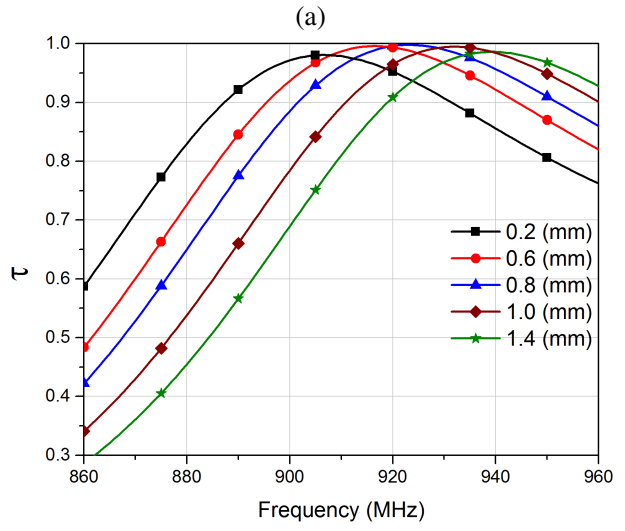

(b)

Fig. 6. Effect on return loss due to (a) A5 and (b) A6.

Variation of the tag antenna impedance with the jaw count is shown in Fig. 2(a) and Fig. 2(b). Both the resistance and reactance of the tag antenna increase with the increase in jaw count. Optimum results are achieved for jaw count of four at $915 \mathrm{MHz}$ for the desired chip.

Variation of the impedance with $A l$ is depicted in Fig. 3(a) and Fig. 3(b). Both resistance and reactance are directly proportional to $A l$ (trace width of jaws). Optimum results are achieved when $A l$ is $1.0 \mathrm{~mm}$. Effect of $B 3$ (radiator width) on the tag antenna impedance is observed in Fig. 4(a) and Fig. 4(b). Resistance is directly proportional to B3. However, it is observed that the variation of reactance is not systematic. When the width is increased from 1.0 to $2.5 \mathrm{~mm}$, reactance increases and then it slightly decreases on further increasing the width. Best results are realized for a width of $2.5 \mathrm{~mm}$ where the resistance of approximately $22 \Omega$ and inductive reactance of $205 \Omega$.

After achieving the antenna impedance close to the chip impedance, the next step is to exactly match it using matching network to avoid any mismatch losses. Matching network consist of series and shunt stubs. As the length and width of the stubs can't be calculated exactly from the smith chart [24], so variation of length and width of the series and stunt stub is carried out in order to exactly match the overall tag impedance with the RFID chip.

The effect of varying series and shunt stubs length on power transmission coefficient [25] is shown in Fig. 5(a) and Fig. 5(b). The tag is perfectly matched at $B 5$ value of $15.8 \mathrm{~mm}$

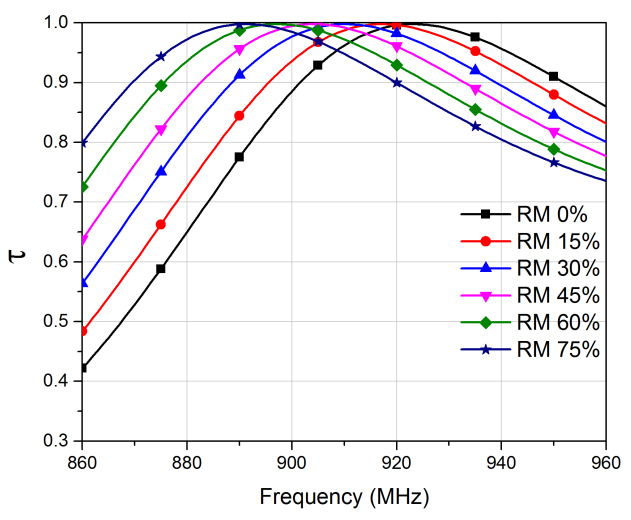

Fig. 7. Computed return loss for different moisture sensors.

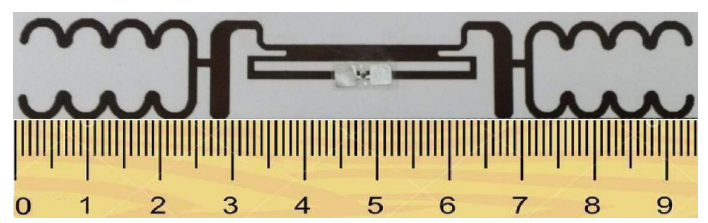

Fig. 8. Printed RFID antenna sensor.

\begin{tabular}{|c|c|c|c|}
\hline $\begin{array}{c}\text { RM } \\
(\%)\end{array}$ & $\begin{array}{c}\text { Impedance } \\
(\Omega)\end{array}$ & $\begin{array}{c}\text { Center Frequency } \\
(\mathrm{MHz})\end{array}$ & $\begin{array}{c}\text { Band Covered } \\
(\mathrm{MHz})\end{array}$ \\
\hline 0 & $20.06+\mathrm{j} 205.11$ & 925 & $902-945$ \\
\hline 15 & $20.3+\mathrm{j} 206$ & 920 & $898-945$ \\
\hline 30 & $21.7+\mathrm{j} 207$ & 915 & $892-939$ \\
\hline 45 & $22.1+\mathrm{j} 208$ & 905 & $884-930$ \\
\hline 60 & $23.5+\mathrm{j} 209.7$ & 900 & $878-924$ \\
\hline 75 & $24.8+\mathrm{j} 210.2$ & 895 & $873-918$ \\
\hline
\end{tabular}

Tab. 2. Computed antenna parameters at different RM.

and $B 6$ value of $3.1 \mathrm{~mm}$. The effect of varying $A 5$ and $A 6$ on power transmission coefficient is shown in Fig. 6(a) and Fig. 6(b). Optimum impedance match is achieved for $A 5$ equal to $1.0 \mathrm{~mm}$ and $A 6$ equal to $0.8 \mathrm{~mm}$.

As the tag is perfectly designed for normal operating condition within the FCC band of $902-928 \mathrm{MHz}$, so the tag is exhibited under different moisture levels and the results are depicted in Fig. 7. The result shows that as the moisture level increases the overall frequency band is shifted to lower value, whereas, the bandwidth remains almost constant. Table 2 shows the detailed antenna parameters of moisture sensor.

\section{Results and Discussion}

In order to calculate the process variation effects, five sample tag antennas are directly printed on Kodak photopaper from Fujifilm Dimatix DMP2800 inkjet printer with silver nano particles based ink (CCI-330 from Cabot Corp.) for reliability check as shown in Fig. 8. This ink is used due to its high diffusion rate and supports better conduction because of its crystalline structure as well as provides stability against moisture effects to some extent. The effect of variation in moisture on antenna impedance is measured 


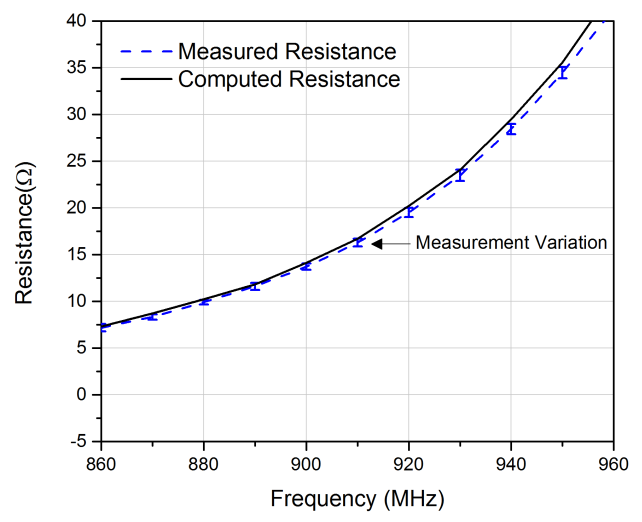

(a)

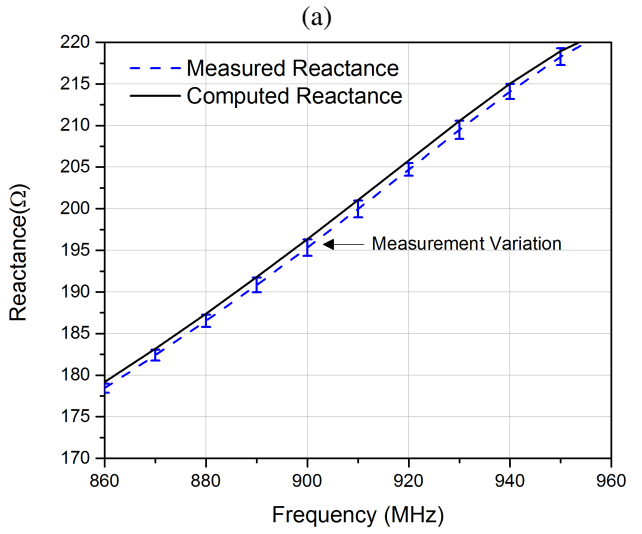

(b)

Fig. 9. Variation in measurement (a) resistance and (b) reactance.

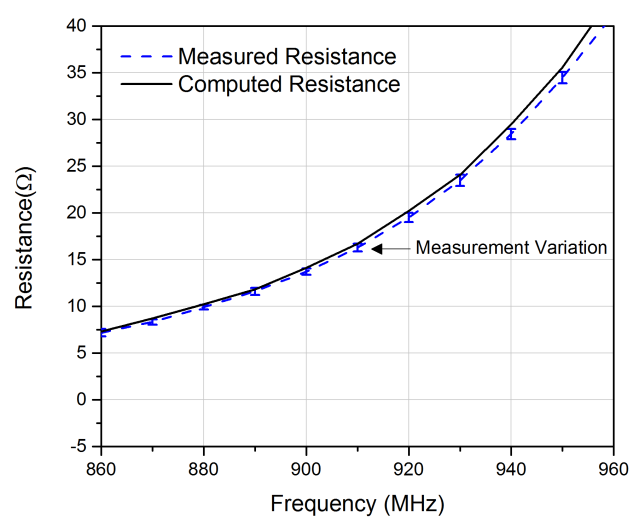

(a)

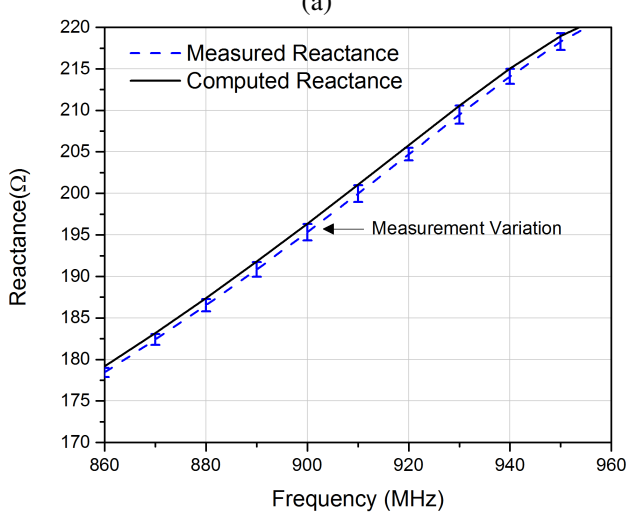

(b)

Fig. 10. Variation in measurement (a) resistance and (b) reactance.

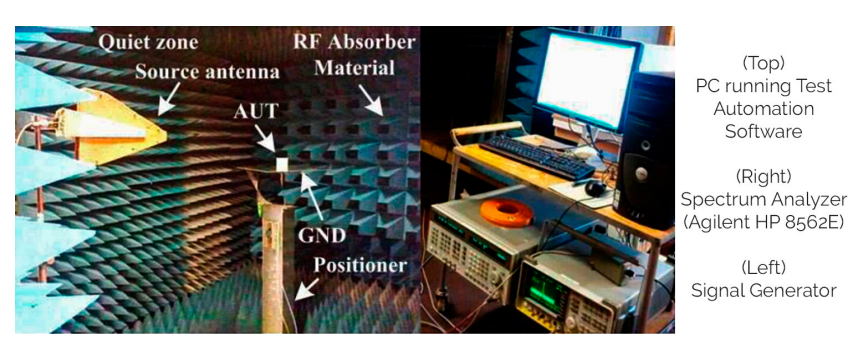

Fig. 11. Measurement setup.

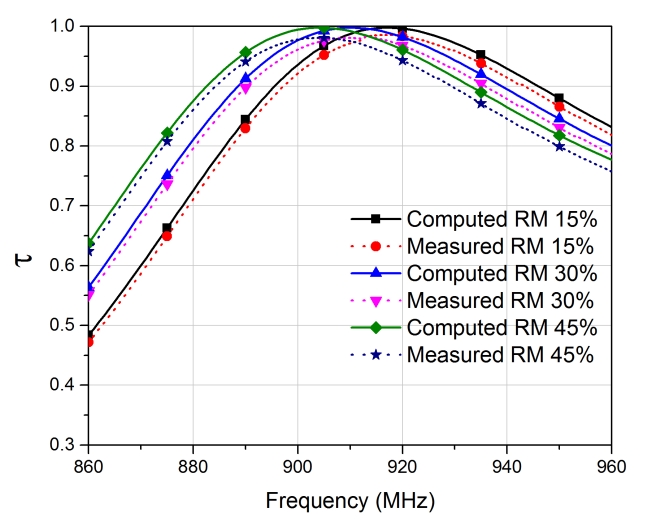

(a)

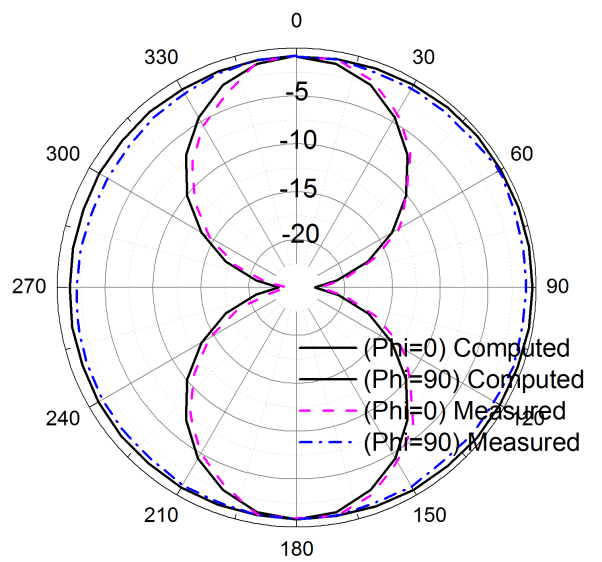

(b)

Fig. 12. (a) Return loss of computed and measured moisture sensor (b) 2D far-field computed and measured radiation pattern.

using Vector Network Analyzer (VNA) placed inside the climate chamber (Wiss Technik WK 11-180). Antenna impedance measurements have been carried out using the differential probe method [26]. After performing short-openload (SOL) calibration of the VNA, the differential probe is connected to the test cables at one end and to the antenna at the other. The S-parameters are obtained which are used to calculate the impedance of the antenna, as in [27].

Figures 10(a) and 10(b) show the measured impedance plots of the proposed antenna, in which the resistance of the antenna varies from $15-24 \Omega$ with a variation of $10 \%$ and reactance shows the linear variation of $9 \%$ within the FCC band of $902-928 \mathrm{MHz}$. It can be observed that the measured and computed impedances of the tag are very close to 


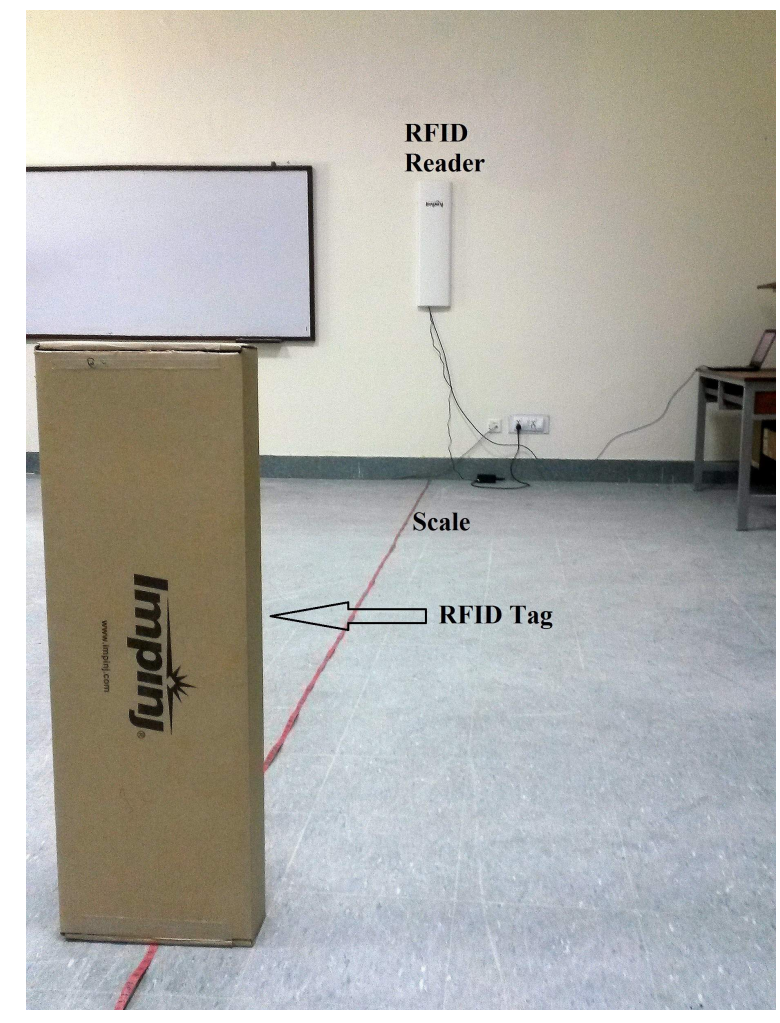

Fig. 13. Measurement setup for the readrange of RFID Tag.

each other. The power transmission coefficient is computed from the measured antenna impedance under different moisture levels. Figure 12(a) shows the measured and computed power transmission coefficient at different moisture levels, in which the tag is readable under FCC band at a distance of 7.5 meters from RFID reader (Impinj R420). The band shifts from higher to lower frequency under different RM conditions, yet remains detectable up to $45 \% \mathrm{RM}$ and as the moisture increases the information from the sensor tag is not fully recoverable.

While interrogating the sensor, the reader's accompanying software MultiReader displays Received Signal Strength Indicator (RSSI) and the Electronic Product Code (EPC) of the tag. The accompanying software has the ability to log the RSSI values with the change in the moisture variation to a log file. However, the MultiReader software cannot process these values to automate the moisture evaluation. For automation, the RSSI value log file is read via a custom-built software application hosted on the same computer. The custom-built software application processes the RSSI values and translate a change in the same to a corresponding update in moisture level evaluation automatically.

The measurement of the antenna's radiation pattern is carried out inside an anechoic chamber setup using Imaging Technique [28]. As the antenna under test (AUT) is symmetric, it is cut into half and positioned on a rounded corner metal plate that acts as a ground plane. One end of the SMA connector penetrates through the rounded corner metal plate at its center and connects to the AUT input port. The AUT is connected using CW2400 silver conductive epoxy that is cured for $4 \mathrm{hrs}$ for achieving maximum conductivity and adhesion. Soft soldering is avoided to connect the AUT to the SMA connector pin, since it requires heating the filler metal above $250{ }^{\circ} \mathrm{C}$ to achieve proper soldering, but this temperature can seriously damage the printed traces on paper substrate.

The other end of the SMA connector is attached to the spectrum analyzer (Agilent HP 8562E) via a coaxial feed line. The rounded corner metal plate is placed on a assembly capable of rotating the AUT in small increments of $5^{\circ}$ to find the $360^{\circ}$ radiation pattern. A continuous wave signal from signal generator excites the AUT [29] and a PC running the test automation software which controls the measurement setup as shown in Fig. 11. Figure 12(b) shows the uniform (omni-directional) normalized computed and measured $2 \mathrm{D}$ radiation patterns. It is observed that the measured and computed radiation patterns are very close to each other. The read-range characteristics of the sensor tag in the near and far-fields are verified using Impinj's UHF RFID reader kit. The boresight read-range of the sensor is measured upto 12.1 meters under room temperature and 7.5 meters is measured with a moisture sensing functionality upto $45 \%$ RM. The readrange measurement setup is shown in Fig. 13. Therefore, the proposed RFID sensor is excellent choice for IoT applications, where moisture sensing is of prime interest.

\section{Conclusion}

An RFID tag antenna with incorporated moisture sensor characteristics is designed, printed and tested. The proposed tag antenna shows optimum results for various moisture levels up to $45 \%$. Design optimization is carried out to reduce the tag antenna size considerably, while minimizing the ink consumption. Proposed tag antenna covers the FCC band of 902-928 MHz with maximum read range of 12.1 meters. Tag antenna is developed on the paper substrate which is flexible, light weight, economical and easily adjustable according to the object, thus making it well suited for IoT applications.

\section{Acknowledgments}

This work was financially supported by Vinnova (The Swedish Governmental Agency for Innovation Systems) and University of Engineering and Techonology Taxila, Pakistan through the Vinn Excellence centers program and ACTSENA research group funding, respectively.

\section{References}

[1] GUBBI, J., BUYYA, R., MARUSIC, S., et al. Internet of Things (IoT): A vision, architectural elements, and future directions. Future Generation Computer Systems, 2013, vol. 29, no. 7, p. 1645-1660. DOI: $10.1016 /$ j.future.2013.01.010 
2] WANT, R., SCHILIT, B. N., JENSON, S. Enabling the internet of things. IEEE Journals and Magazines, 2015, vol. 48, no. 1, p. 28-35. DOI: 10.1109/MC.2015.12

[3] TRUONG, H. L., DUSTDAR, S. Principles for engineering IoT cloud systems. IEEE Cloud Computing, 2015, vol. 2, no. 2, p. 68-76. DOI: 10.1109/MCC.2015.23

[4] KHAN, M. S., ISLAM, M. S., DENG, H. Design of a reconfigurable RFID sensing tag as a generic sensing platform towards the future internet of things. IEEE Internet of Things Journal, 2014, vol. 1, no. 4, p. 300-310. DOI: 10.1109/JIOT.2014.2329189

[5] ABAD, E., PALACIO, F., NUIN, M., et al. RFID smart tag for traceability and cold chain monitoring of foods: Demonstration in an intercontinental fresh fish logistic chain. Journal of Food Engineering, 2009, vol. 93, no. 4, p. 394-399. DOI: $10.1016 /$ j.jfoodeng.2009.02.004

[6] AMIN, Y., CHEN, Q., ZHENG, L. R., et al. Development and analysis of flexible UHF RFID antennas for 'Green' electronics. Progress In Electromagnetics Research, 2012, vol. 130, p. 1-15. DOI: 10.2528/PIER12060609

[7] OPREA, A., COURBAT, J., BARSAN, N., et al. Temperature, humidity and gas sensors integrated on plastic foil for low power applications. Sensors and Actuators B: Chemical, 2009, vol. 140, no. 1 p. 227-232. DOI: $10.1016 /$ j.snb.2009.04.019

[8] JANKOWSKI P. M., KALITA W., SKOCZYLAS M., et al. Modelling and Design of HF RFID Passive Transponders with Additional Energy Harvester. International Journal of Antennas and Propagation, 2013, vol. 2013, p. 1-10. DOI: $10.1155 / 2013 / 242840$

[9] TRABELSI, S., NELSON, S. O. Microwave sensing method for simultaneous and independent determination of bulk density and moisture content of shelled peanuts. IEEE Antennas and Propagation Society International Symposium, 2006, p. 3187-3190. DOI: 10.1109/APS.2006.1711288

[10] SIDEN, J., ZENG, X., UNANDER, T., et al. Remote moisture sensing utilizing ordinary RFID tags. Proceedings of IEEE Sensors, 2007, p. 308-311. DOI: 10.1109/ICSENS.2007.4388398

[11] KIM, S., LE, T., TENTZERIS, M. M., et al. An RFID-enabled inkjet-printed soil moisture sensor on paper for 'smart' agricultural applications. Proceedings of IEEE sensors, 2014, p. 1507-1510. DOI: 10.1109/ICSENS.2014.6985301

[12] Milne, S. D., CONNOLly, P., HAMAD, H. A., et al. Development of wearable sensors for tailored patient wound care. Proceedings of 36th Annual International Conference of the IEEE Engineering in Medicine and Biology Society, 2014, p. 618-621. DOI: $10.1109 /$ EMBC.2014.6943667

[13] SIDEN, J., KOPTIOUG, A., GULliKSSON, M. The 'smart' diaper moisture detection system. Proceedings of IEEE MTT-S International Microwave Symposium Digest, 2004, p. 659-662. DOI: 10.1109/MWSYM.2004.1336073

[14] SGOUROPOUlOS, D., SPYROU, E., SIANTIKOS, G. Counting and tracking people in a smart room: An IoT approach. Proceedings of 10th International Workshop on Semantic and Social Media Adaptation and Personalization, 2015, p. 1-5. DOI: 10.1109/SMAP.2015.7370087

[15] OlAODE, O. O., PALMER, W. D., JOINES, W. T. Characterization of meander dipole antennas with a geometry based, frequency independant lumped element model. IEEE Antennas and Wireless Propagation Letters, 2012, vol. 11, p. 346-349. DOI: 10.1109/LAWP.2012.2191380
[16] OLAODE, O. O., PALMER, W. D., JOINES, W. T. Effects of meandering on dipole antenna resonant frequency. IEEE Antennas and Wireless Propagation Letters, 2012, vol. 11, p. 122-125. DOI: 10.1109/LAWP.2012.2184255

[17] LAI, X. Z., XIE, Z. M., CEN, X. L. Design of dual circularly polarized antenna with high isolation for RFID applications. Progress In Electromagnetics Research, 2013, vol. 39, p. 25-39. DOI: $10.2528 /$ PIER13030609

[18] SZARKA, G. D., BURROW, S. G., PROYNOV, P. P., et al. Maximum power transfer tracking for ultralow-power electromagnetic energy harvesters. IEEE Transactions on Power Electronics, 2014, vol. 29, no. 1, p. 201-212. DOI: 10.1109/TPEL.2013.2251427

[19] LOO, C. H., ELMAHGOUB, K., YANG, F. Chip impedance matching for UHF RFID tag antenna design. Progress In Electromagnetics Research, 2008, vol. 81, p. 359-370. DOI: 10.2528/PIER08011804

[20] LIU, C., ZHANG, L., PENG, J., et al. Temperature and moisture dependence of the dielectric properties of silica sand. Journal of Microwave Power and Electromagnetic Energy, 2013, vol. 47, no. 3 , p. 199-209. DOI: 10.1080/08327823.2013.11689858

[21] MULEY, P. D., BOLDOR, D. Investigation of microwave dielectric properties of biodiesel components. Bioresource Technology, 2013 , vol. 127, p. 165-174. DOI: 10.1016/j.biortech.2012.10.008

[22] CHENG, Y. L., LEON, K. W., HUANG, J. F., et al. Effect of moisture on electrical properties and reliability of low dielectric constan materials. Microelectronic Engineering, 2014, vol. 114, p. 12-16. DOI: 10.1016/j.mee.2013.08.018

[23] BHARGAVA, N., JAIN, R., JOSHI, I., et al. Effect of frequency and moisture variation on dielectric properties of pearl millet in powder form. Journal of Environmental Nanotechnology, 2013, vol. 2, p. 1-5. DOI: 10.13074/jent.2013.02.nciset31

[24] MARROCCO, G. The art of UHF RFID antenna design: impedance-matching and size-reduction techniques. IEEE Antennas and Propagation Magazine, 2008, vol. 50, no. 1, p. 66-79. DOI: 10.1109/MAP.2008.4494504

[25] JANKOWSKI P. M., KAWALEC D., WEGLARSKI M. Antenna Design for Semi-Passive UHF RFID Transponder with Energy Harvester. Radioengineering, 2015, vol. 24, no. 3, p. 722-728. DOI: $10.13164 /$ re.2015.0722

[26] AMIN Y., CHEN Q., ZHENG, L.R, et al. 'Green' wideband logspiral antenna for RFID sensing and wireless applications. Journal of Electromagnetic Waves and Applications, 2012, vol. 26, no. 14, p. 2043-2050. DOI: $10.1080 / 09205071.2012 .724767$

[27] JANKOWSKI P. M., PITERA G., WEGLARSKI M. The Impedance Measurement Problem in Antennas for RFID Technique. Metrology and Measurement Systems, 2014, vol. 21, no. 3, p. 509-520. DOI: $10.2478 / \mathrm{mms}-2014-0043$

[28] AMIN, Y., CHEN Q., ZHENG L. R., et al. Design and fabrication of wideband archimedean spiral antenna based ultra-low cost 'Green' modules for RFID sensing and wireless applications. Progress in Electromagnetic Research, 2012, vol. 130, p. 241-256. DOI: 10.2528/PIER12070807

[29] JANKOWSKI, P. M., WEGLARSKI, M. A Method for Measuring the Radiation Pattern of UHF RFID Transponders. Metrology and Measurement Systems, 2016, vol. 23, no. 2, p. 163-172. DOI: $10.1515 / \mathrm{mms}-2016-0018$ 


\section{About the Authors...}

Umar Hasan KHAN received his BS degree in Electrical Engineering from Centre for Advancement Studies in Engineering, Islamabad in the year 2009, and his MS degree is in Microwave Engineering from National University of Science and Technology in the year 2013. He joined University of Engineering and Technology, Taxila the same year as a fulltime $\mathrm{PhD}$ researcher where he is working towards his doctoral degree focused on RFID antennas.

Bilal ASLAM received his BS degree in Electrical Engineering from University of Engineering and Technology, Taxila in the year 2007, and his MS degree in Electrical Engineering from National University of Science and Technology in the 2013. The same year, he joined the University of Engineering and Technology, Taxila as a full-time $\mathrm{PhD}$ researcher where he is pursuing his doctoral degree focused on RFID antennas.

Muhammad Awais AZAM received his PhD degree in Pervasive and Ubiquitous Computing from London, UK in 2012. he is working as an Assistant Professor at the Department of Computer Engineering, UET Taxila, Pakistan. He leads a research team of MS and $\mathrm{PhD}$ students in the area of pervasive and ubiquitous computing. His research interest includes network architecture, communication protocols, network security, embedded systems, ambient intelligence, wireless communications, opportunistic networks and recommender systems.

Yasar AMIN is Chairman and Associate Professor of Telecommunication Engineering Department, University of Engineering and Technology Taxila, Pakistan. He is founder of ACTSENA Research Group at UET Taxila, Pakistan. He has done his BSc in Electrical Engineering in 2001 with specialization in Telecommunication and MSc in Electrical Engineering in 2003 with specialization in System-on Chip Design from Royal Institute of Technology (KTH), Sweden. His $\mathrm{PhD}$ is in Electronic and Computer Systems from Royal Institute of Technology (KTH), Sweden, with research focus on printable green RFID antennas for embedded sensors, while has MBA in Innovation and Growth from Turku School of Economics, University of Turku, Finland. He has done several specialized courses from Stanford University, California, USA and Massachusetts Institute of Technology (MIT), USA. He has supervised over 15 M.Sc. thesis, and presently supervising 8 doctoral thesis. He is presently serv- ing as leading Guest Editor at two International Journals and an active reviewer of more than a dozen well reputed International journals. He has contributed to over 20 journal papers, over 30 reviewed international conference papers. Dr. Yasar is a member of IEEE, IET, ACM and ACES.

Hannu TENHUNEN is chair professor of Electronic Systems at Royal Institute of Technology (KTH), Stockholm, Sweden. Prof. Tenhunen has held professor position as full professor, invited professor or visiting honorary professor in Finland (TUT, UTU), Sweden (KTH), USA (Cornel U), France (INPG), China (Fudan and Beijing Jiatong Universities), and Hong Kong (Chinese University of Hong Kong), and has an honorary doctorate from Tallinn Technical University. He has been director of multiple national large scale research programs or being an initiator and director of national or European graduate schools. He has actively contributed on VLSI and SoC design in Finland and Sweden via creating new educational programs and research directions, most lately at European level as being the EU-level Education Director of the new European flagship initiative European Institute of Technology and Innovations (EIT), and its Knowledge and Innovation Community EIT ICT Labs.

Prof. Tenhunen has been active in promoting the innovation system and innovation support mechanism in research and education both at national and European level. Prof. Tenhunen has been a board member in science parks, startup companies, and has served as advisor or expert for high technology companies and venture capitalists, as well as evaluator for EU and national programs and research institutes. He has supervised over 70 M.Sc. thesis, 39 doctoral thesis, and 8 post-doc. From his doctoral students and post-docs, as of today, 21 are currently professors and associate professors. Prof. Tenhunen has served in Technical Program Committee's of all major conferences in his area, have been general chairman or vice-chairman or member of Steering Committee of multiple conferences in his core competence areas. He has been one of the founding editorial board member of 3 scientific journal, have been quest editor for multiple special issues of scientific journals or books, and have contributed numerous invited papers to journals. He has contributed to over 110 journal papers, over 625 reviewed international conference papers, over 170 non-reviewed papers, local conference papers, or other publications, and 9 international patents granted in multiple countries. Prof. Tenhunen is member of Academy of Engineering Science of Finland. 